\title{
Proceeding
}

Supplementary Issue: Rio 2016 Olympic Games Fourth Anniversary Special Edition. Olympic Studies Forum, 21-24 October 2020. Olympic Studies Research Group, Pontifical Catholic University of Rio Grande do Sul (GPEO PUCRS), Brazil

\section{Sport, Olympic educational values and social inclusion: Possible approaches}

\section{Esporte, valores educacionais olímpicos e inclusão social: Possíveis abordagens}

\author{
LEONARDO PEROVANO-CAMARGO ${ }^{1} \square$, LEONARDO JOSÉ MATARUNA-DOS-SANTOS², OTÁVIO \\ TAVARES 1
}

${ }^{1}$ Federal University of Espirito Santo, Brazil

${ }^{2}$ Canadian University of Dubai, United Arab Emirates

\begin{abstract}
Throughout history, sport has been used as a tool of education in values, characterized as an axiological metalanguage. In the contemporary world, a series of social intervention initiatives uses sport to achieve social inclusion, crime prevention, among other social objectives. Scheila Antunes (2018) defined these social intervention initiatives as 'Sports Projects of a Social Character' (PECS), which can be defined as undertakings of non-specific social assistance organizations, which offer sports modalities as the main strategy of action to transform a portion of a social context. In this way, some projects have adopted the values of the Olympic Movement as a reference for the development of their objectives by operating the teaching of Olympic values. These initiatives are generically known as "Olympic education". This essay introduces an investigation between the relations of sport, Olympic education and social inclusion, having as an outline the Olympic education programs in Brazil, which are certified by the Brazilian Committee Pierre de Coubertin. It concludes with the survey of evidence - in the sense of Ginzburg's indicative paradigm - that can be related to Donnelly's four dimensions of social inclusion. Despite the claim that the legacy of Olympic education should be a bridge between the pursuit of excellence for elite athletes, and the pursuit of a child's dreams (Binder, 2012), social inclusion would only be effective after part of these dreams becomes reality in their life trajectories.
\end{abstract}

Keywords: Sport pedagogy; Human development; Life trajectories.

\section{Cite this article as:}

Perovano-Camargo, L., Mataruna-Dos-Santos, L.J., \& Tavares, O. (2021). Sport, Olympic educational values and social inclusion: Possible approaches (in Portuguese). Journal of Human Sport and Exercise, 16(1 proc), S74S83. doi:https://doi.org/10.14198/jhse.2021.16.Proc1.07

Corresponding author. Federal University of Espirito Santo, Brazil. https://orcid.org/0000-0001-8587-5276

E-mail: leonardoperovano@gmail.com

Supplementary Issue: Rio 2016 Olympic Games Fourth Anniversary Special Edition. Olympic Studies Forum, 21-24 October 2020. Olympic Studies Research Group, Pontifical Catholic University of Rio Grande do Sul (GPEO PUCRS), Brazil.

JOURNAL OF HUMAN SPORT \& EXERCISE ISSN 1988-5202

(c) Faculty of Education. University of Alicante

doi:10.14198/jhse.2021.16.Proc1.07 


\section{RESUMO}

No decorrer da história, o esporte tem sido utilizado como meio ou ferramenta de educação em valores, caracterizando-se como uma metalinguagem axiológica. No mundo contemporâneo, uma série de iniciativas de intervenção social se utiliza do esporte como ferramenta para alcançar a inclusão social, a prevenção de delitos, entre outros objetivos sociais. Scheila Antunes (2018) definiu estas iniciativas de intervenção social como 'Projetos Esportivos de Caráter Social' (PECS), que podem ser definidos como empreendimentos de organizações não-específicas da assistência social, que têm na oferta de modalidades esportivas, a principal estratégia de ação para transformar uma parcela de um contexto social. Desta forma, alguns projetos têm adotado os valores do Movimento Olímpico como referência para o desenvolvimento de seus objetivos operacionalizando 0 ensino de valores olímpicos. Essas iniciativas são genericamente conhecidas como "educação olímpica". Esse ensaio introduz uma perquirição entre as relações do esporte, da educação olímpica e da inclusão social, tendo como recorte os programas de educação olímpica no Brasil, que são certificados pelo Comitê Brasileiro Pierre de Coubertin. Conclui-se com o levantamento de indícios - no sentido do paradigma indiciário de Ginzburg - que podem se relacionar com as quatro dimensões da inclusão social de Donnelly. Apesar da afirmação de que o legado da educação olímpica deveria ser uma ponte entre a busca pela excelência dos atletas de elite, e a busca pelos sonhos de uma criança (Binder, 2012), a inclusão social só seria efetiva a partir da realização de parte desses sonhos em suas trajetórias de vida. Palavras-Chave: Pedagogia do esporte; Desenvolvimento humano; Trajetórias de vida. 


\section{INTRODUÇÃO}

No decorrer da história, o esporte tem sido utilizado como meio ou ferramenta de educação em valores, caracterizando-se como uma metalinguagem axiológica. No mundo contemporâneo, uma série de iniciativas de intervenção social se utiliza do esporte como ferramenta para alcançar a inclusão social, a prevenção de delitos, entre outros objetivos sociais. Scheila Antunes $(2018)^{1}$ definiu estas iniciativas de intervenção social como 'Projetos Esportivos de Caráter Social' (PECS). Segundo esta pesquisadora, os PECS podem ser definidos como:

[...] aqueles empreendimentos de organizações não-específicas da assistência social, que têm na oferta de uma ou mais modalidades esportivas, a principal estratégia de ação para transformar uma parcela da realidade, diminuindo ou eliminando um déficit, ou solucionando um problema social (Antunes, 2018, p. 22).

Neste contexto, alguns projetos têm adotado os valores do Movimento Olímpico como referência para 0 desenvolvimento de seus objetivos ou mesmo operacionalizações didático-pedagógicas do ensino de valores olímpicos. Essas operacionalizações são genericamente conhecidas como "educação olímpica".

Todavia, revisões como as de Stegeman e Janssens (2004) na Holanda, Bailey (2005) no Reino Unido, e o estudo de Scheila Antunes (2018) no Brasil apontam para a existência de resultados contraditórios, limitações metodológicas e, portanto, a carência de evidências conclusivas sobre uma relação de causalidade estabelecida entre a prática de esportes, a inclusão social e/ou comportamento pró-social. Desta forma, seriam necessários novos estudos em projetos sociais que investiguem as relações entre a educação olímpica e seus benefícios pró-sociais.

A chamada "educação olímpica" (educação em valores por meio do esporte tendo como referência os valores, símbolos, histórias e rituais do Movimento Olímpico) é fonte de inspiração em muitos países, similarmente, para obter êxito em seus objetivos sociais. Existe um discurso do senso comum que afirma ser o esporte capaz de promover múltiplos efeitos benéficos entre seus praticantes (Stegeman; Janssens, 2004; Bailey, 2005; Nichols, 2007). Entretanto, perguntas como "Quais são as condições necessárias para que o esporte produza resultados benéficos?" (Patriksson, 1995, p. 128, apud Bailey, 2005, p. 84) precisariam ser perguntadas e respondidas com mais frequência, visto que a crença no esporte como uma panaceia capaz de mudar as vidas das pessoas de forma integral não é acompanhada de evidências suficientes que sustentem essas crenças (Vilaça; Gawryszewski; Palma, 2014).

A concepção da utilização do esporte como ferramenta pedagógica remete ao próprio conceito de educação, ambos originados na Grécia Antiga. A paideia² grega clássica considerava os exercícios gímnicos como

\footnotetext{
${ }^{1}$ Optou-se por colocar o primeiro nome, ou utilizar designação que identifique o gênero de autoria, na intenção de dar visibilidade acadêmica à obra de autoras que tradicionalmente são tratadas com pronome masculino ao serem citadas pelo sobrenome paterno ou do cônjuge. Opção diversa da Carta Olímpica, que entende o emprego do gênero masculino como referência a abarcar também o feminino a não ser que haja alguma disposição contrária (COI, 2015).

${ }^{2}$ A palavra 'paideia' é similar a 'cultura' na análise da sociedade grega clássica, ao referir-se ao processo de formação da pessoa humana. Cultura "no significado referente à formação da pessoa humana individual, essa palavra corresponde ainda hoje ao que os gregos chamavam Paideia e ao que os latinos, na época de Cícero e Varrão, indicavam com a palavra humanitas: educação do homem como tal, ou seja, educação devida às 'boas artes' peculiares do homem, que o distinguem de todos os outros animais. As boas artes eram a poesia, a eloquência, a filosofia etc., às quais se atribuía valor essencial para aquilo que o homem é e deve ser, portanto, para a capacidade de formar o homem verdadeiro, o homem na sua forma genuína e perfeita. Para os gregos, a
} 
uma aspiração cultural coletiva, sendo esta concepção retomada em diversos períodos históricos, durante mais de 25 séculos, com diversas propostas pedagógicas e, contemporaneamente, com características científico-pedagógicas. É no contexto da formação do mundo moderno que o desenvolvimento da pedagogia em bases filosóficas e científicas retoma, não sem algum debate e muitas distinções específicas, o esporte como meio educacional (DaCosta, 2009), proporcionando a percepção de um paradigma 3 .

"O esporte seria, como Platão pensou, uma ferramenta valiosa em inspirar boas atitudes e valores nos jovens? Ou deveríamos ser mais pragmáticos e não esperar tanto? O esporte não seria tão especial, mas poderia refletir outros fenômenos e processos sociais?" (Breivik, 1998, p. 103). Esta perspectiva histórica permite considerar o esporte contemporâneo como "carreador de valores sociais" (Breivik, 1998), podendo definí-lo como uma "metalinguagem axiológica não verbal e não escrita que pode ser generalizada" (DaCosta, 2009, p. 23).

Em meados de 1890, o intelectual francês Pierre de Coubertin inicia um movimento que pregava a unidade do corpo, mente e caráter em busca de uma educação harmoniosa e que, posteriormente, daria origem ao Movimento Olímpico. Neste contexto, concebia que os treinamentos atléticos deveriam ser contemplados em uma abordagem mais ampla. $O$ objetivo era o de autodesenvolvimento por meio das conquistas atléticas. Desta maneira, as atividades esportivas não deveriam focar somente na performance atlética, mas levar à "perfeição humana", ao "aprimoramento do homem", à construção de seu caráter, de sua educação, de sua moral (Grupe, 1991).

Estudos recentes em treinamento esportivo (Morente, 2020) procuram uma suposta modernidade entre as relações de teorias contemporâneas e as utilizadas da Grécia Antiga, contextualizando os preceitos do passado ao estado da arte atual. Mais de mil anos de Jogos da Antiguidade (776 AC a 393 DC) são um recorte amplo para perceber diversas alterações em suas concepções, crenças e práticas. Morente (2020) encontrou relações significativas em elementos ligados aos treinamentos esportivos, dando certo caráter de atualidade a concepções do passado. Porém, no âmbito dos valores educacionais do esporte (uma das fontes de inspiração de Coubertin também foi a Grécia Antiga), essas concepções também se atualizariam satisfatoriamente?

Os ideais de Coubertin se deparam com um paradoxo na atualidade, pois, segundo Silvana Goellner (2005, p. 82), ao mesmo tempo em que os Jogos Olímpicos remetem à "solidariedade, consagração, celebração, convivência, fraternidade e inclusão", também trazem, por outro lado, "registros de nacionalismos exacerbados, exploração comercial e econômica, corrupção, especialização precoce, doping, violência e discriminação sexual".

Uma ambiguidade que surge como consequência da utilização do esporte, em sua perspectiva extrínseca, com a intenção de promover a inclusão social, reside na consideração do que seria a exclusão social, tão elencada como um elemento a ser "resolvido" com o auxílio do esporte. Bailey (2005) argumenta que enquanto alguns consideram a exclusão social como desemprego, baixas habilidades, baixa remuneração, moradia precária, ambientes com altas taxas de criminalidade, saúde deficiente e famílias desestruturadas,

cultura nesse sentido foi a busca e a realização que o homem faz de si, isto é, da verdadeira natureza humana" (Abbagnano, 2007, p. 225).

3 paradigma pode ser tido como um modelo ou um exemplo. Há também um paradigma da ciência no qual um conjunto de teses reforça um possível conceito de verdade científico temporário. Platão considerou a palavra paradigma enquanto modelo ao considerar $P$ o mundo de seres eternos e o mundo sensível como imagem desse mundo. Já Aristóteles utilizou a palavra paradigma como significado de exemplo (Abbagnno, 2007). 
outros argumentam ser essa concepção uma confusão das consequências da exclusão social com as suas causas. Os motivos que levariam as consequências citadas seriam as diversas mudanças sociais que excluiriam as pessoas das trocas normais, práticas e direitos dentro da sociedade moderna. Deste modo, considerando que exclusão e inclusão são dimensões inseparáveis da mesma questão, adotamos as categorias de inclusão social definidas por Donnelly (1996) como referência teórica. Para este autor, a discussão sobre inclusão social pode ser contida em quatro dimensões: [a] Dimensão espacial (definida pelas distâncias sociais e econômicas entre os indivíduos), [b] Dimensão relacional (definida pelo senso de pertencimento a algum grupo ou comunidade), [c] Dimensão Funcional (definida pela aquisição de habilidades), e [d] Dimensão de Poder (definida pela aquisição de capacidade decisória e crítica).

O esporte revela desigualdades explícitas apoiadas na performance atlética (perspectiva intrínseca), entretanto, em termos sociais (perspectiva extrínseca), ele é geralmente considerado como um "nivelador" social, superando desigualdades sociais já existentes. 0 esporte olímpico era referido por Coubertin com uma "democracia de habilidades", com base em sua visão idealizada baseada na participação e não nos resultados. Sendo a democracia uma condição para a equidade, aparentemente o fato de alguém ter sido selecionado como atleta olímpico o faria igual entre os outros atletas olímpicos, entretanto, sabe-se que esses atletas já fazem parte de um grupo de elite seleto que demonstra as desigualdades de oportunidades em diversos níveis sociais, entre nações, classes sociais, questões étnicas e de gênero (Donnelly, 1996).

A participação nas atividades esportivas e na educação física teria assim o "potencial" para melhorar os parâmetros da exclusão social nas dimensões expostas, especialmente entre os mais jovens (Bailey, 2005). Entretanto, sabe-se que qualquer proposta de ensino é pautada em uma "concepção de valor" (Zabala, 1998). Deste modo, esse potencial só poderia se transformar em uma realidade, se fosse fundada em resultados concretos na alteração das dimensões de inclusão/exclusão em favor dos participantes, baseada em uma concepção de valor pró-social que se cristalize e cumpra sua função social.

Breivik (1998) conceitua ontologicamente os valores em três visões: a primeira seria a Platônica, visão idealista onde existiriam valores objetivos e eternos que jamais mudariam, podendo classificar indivíduos e sociedades em variados graus, os comparando com esses valores eternos. A segunda visão dos valores, proposta por Breivik, é a cultural, histórica e em diversas maneiras, uma visão relativista. Os valores seriam uma construção social da realidade, não sendo independentes e eternos, mas relativos e temporais, criados pelas interações humanas. A terceira visão se aproxima mais da segunda ao entender que os valores seriam simplesmente uma expressão individual de preferências subjetivas, sendo o individualismo experimental capaz de explicar todas as decisões e comportamentos de atores individuais.

A respeito dos valores educacionais do esporte especificamente, Carr (1998) também traz três modelos de argumentação, em sua relação com a moral. O primeiro modelo afirma que esportes, jogos ou outras atividades físicas possuem características como competição e agressão que podem ser vistas como moralmente negativas; sendo assim, seu ensino possuiria apenas valor educacional moral negativo. 0 segundo modelo demonstra que esportes, jogos e atividades físicas, por possuírem características como cooperação e espírito de equipe (moralmente positivas), seu ensino possuiria apenas valor educacional moral positivo. Em terceiro lugar, o modelo que argumenta que esportes, jogos e atividades físicas não demonstram claramente características inerentes de moral negativa ou positiva. Portanto, essas atividades estariam "à parte" das questões morais mais amplas e, portanto, neutras de um ponto de vista educacional (Carr, 1998). 
Apesar da dúvida sobre até que ponto o esporte é descontinuado do resto da vida humana, a visão do que é considerado ou não esporte e a própria noção de "espírito esportivo" de determinada sociedade poderia ser considerada o "barômetro do clima moral" (Carr, 1998) dela mesma. Desse modo, assim como sociedades contemporâneas civilizadas não poderiam tolerar um líder religioso que defendesse o retorno aos sacrifícios humanos, ou um cientista que defendesse o uso de pessoas com problemas genéticos para experimentações médicas, também não deveria tolerar o retorno aos dias de combates de gladiadores, em que escravos lutavam até a morte para o deleite de multidões sádicas (Carr, 1998).

\section{EDUCAÇÃO EM VALORES E PROJETOS ESPORTIVOS DE CARÁTER SOCIAL NO BRASIL}

Situando a discussão sobre projetos/programas sociais esportivos no Brasil, temos como pioneira a pesquisadora Alba Zaluar, com estudos datados da década de 1980. Após cerca de três décadas de pesquisas, constatou-se que houve um crescimento no número de projetos sociais, tornando-se um padrão de ação social alicerçado no próprio Estado, não mais apenas uma prática complementar à ação estatal.

Kravchychyn e Oliveira (2015), em um estudo de revisão sobre os projetos e programas sociais que se utilizam do esporte no Brasil, identificaram perspectivas apologísticas, críticas e pedagógicas nas produções científicas. As perspectivas apologísticas partem do princípio de que os aprendizados e vivências esportivas podem oferecer "conteúdos simbólicos e comportamentos úteis para crianças e jovens enfrentarem problemas de suas vidas, além de municiá-los de novas perspectivas de vida" (Stigger; Thomassim, 2013, p. 5). Zaluar (1994) também parte desse ponto de vista ao apontar a visão positiva do esporte, destacando "as qualidades de caráter, como o companheirismo, a força de vontade, o fair play, todas elas experimentadas e vividas concretamente na prática do esporte" (p. 92). As perspectivas críticas apontam essas iniciativas como "produtos de um modelo governamental neoliberal, que repassa à sociedade civil responsabilidades do Estado" (Kravchychyn; De Oliveira, 2015, p. 152). Por fim, as perspectivas pedagógicas, que apontam a educação física como área acadêmica que busca compreender o esporte enquanto objeto de estudo e intervenção, buscando críticas, proposições e referências em suas análises, para sua atuação pedagógica nesses projetos e programas. Podemos afirmar que a prática esportiva que não leva em conta os valores que estão sendo transmitidos, e sem uma intencionalidade pró-social explícita, teria dificuldades em poder apontar evidências de alguma possível melhora coletiva.

Uma revisão sobre projetos/programas sociais esportivos no Brasil (PEROVANO-CAMARGO, TAVARES, ainda não publicada) identificou diversos estudos sobre inclusão social, e outros sobre educação olímpica, mas não encontrou estudos que aliassem ambos, mesmo sendo a inclusão social um elemento importante que pode se relacionar ao Olimpismo, demonstrando uma lacuna na literatura. Desta forma, a verificação do potencial do uso do esporte para melhorar os parâmetros da inclusão social necessitaria de mais estudos que identificassem que o potencial do esporte só seria transformado em realidade levando em consideração resultados concretos na alteração das dimensões de inclusão social em favor dos participantes.

\section{EDUCAÇÃO EM VALORES E EDUCAÇÃO OLÍMPICA NO BRASIL: PRIMEIRAS APROXIMAÇÕES}

Em toda a América Latina, no momento em que escrevemos este texto, só existem projetos/programas sociais certificados de educação olímpica no Brasil. Esses programas ${ }^{4}$, credenciados pelo Comitê Brasileiro

\footnotetext{
${ }^{4}$ Cabe ressaltar que o coordenador da Fundação Tênis se refere ao mesmo como um programa e não um projeto. Ao passo que projetos sociais têm a característica da temporalidade reduzida, muitos não durando mais de um ano, um programa pressupõe uma durabilidade, podendo apresentar uma alteração maior em determinada realidade e conquista de objetivo social, a partir do momento que se pode avaliar e alterar percursos, perceber resultados (eficiência - custo, eficácia - resultado e efetividade -
} 
Pierre de Coubertin (CBPC) e ratificados pelo International Pierre de Coubertin Comittee (IPCC), são a Estação Conhecimento localizada em Serra (ES) e a Fundação Tênis que possui sedes nos estados de São Paulo e Rio Grande do Sul. A Estação Conhecimento faz parte de um programa da Fundação Vale chamado Brasil Vale Ouro que possui núcleos em Brumadinho (MG), Arari (MA), Marabá e Tucumã (PA), além de Serra (ES). Entretanto, apenas o núcleo localizado no Espírito Santo recebeu certificação do Comitê Brasileiro Pierre de Coubertin.

Levantamentos prévios para uma pesquisa em desenvolvimento na Estação Conhecimento (EC) e Fundação Tênis (FT) identificaram que, além de serem os únicos programas certificados em educação olímpica na América Latina, também só abrem vagas para crianças e jovens em situação de vulnerabilidade social $^{5}$, demonstrando uma preocupação preliminar com um parâmetro de inclusão social.

De fato, em matéria veiculada em um jornal local sobre a Estação Conhecimento, as lideranças afirmam que o objetivo do programa é formar "cidadãos honrados e responsáveis". Acrescenta-se que o aluno "deve ser um bom atleta, um excelente cidadão [...] um bom cidadão 'para' a sociedade". De forma análoga, o estatuto original da Fundação do Tênis propõe também "dar acesso a experiências desportivas que visem formar cidadãos 'para' a sociedade".

Considerando o esporte como uma metalinguagem axiológica, o ensino da prática esportiva, portanto, comunicaria algo. Esse algo, no caso da Estação Conhecimento e da Fundação Tênis, seriam os valores educacionais do Movimento Olímpico por meio da educação olímpica, que está imbuída de valores (conteúdo atitudinal). Todavia, a comunicação é dialógica e um ensaio de análise do discurso pode referirse a macros de significados e sentidos percebidos. Ou seja, precisamos resguardar a hipótese de que 0 ensino em valores olímpicos possa ser recepcionado de maneira diferente e/ou desigual pelas crianças e jovens praticantes.

Desejar que os alunos não sejam apenas atletas, mas também cidadãos, é um objetivo interessante a seguir, porém quando um treinamento final é sugerido, pode-se supor que não teria havido algo previamente dado? Se você vai formar um cidadão, qual é o entendimento de cidadania exposto? Se você usar os adjetivos "honrado e responsável" para os cidadãos, seria presumido que não haveria honra e responsabilidade antes de entrar no programa? Um cidadão "excelente" poderia ser relacionado ao conceito de "excelência" de Coubertin, dando o melhor de si no jogo e na vida, sendo uma pista positiva para se comunicar com os alunos do programa?

Em um diálogo preliminar com a gestão da Estação Conhecimento, foi esclarecido que são oferecidas diversas atividades culturais que acontecem no mesmo espaço das atividades esportivas, mas, por serem simultâneas, não seria possível conciliar a participação das crianças e jovens, entre outras coisas, porque os alunos vão ao programa durante o contra turno escolar, o que impossibilita a participação em dois programas ao mesmo tempo.

\footnotetext{
impacto) e expor os praticantes por mais tempo aos seus currículos. De forma análoga, a Estação Conhecimento que é gerida pela Fundação Vale (usando o nome Brasil Vale Ouro para ações esportivas), também admite desejar ser "um programa de esporte que tenha importante contribuição e significado para o desenvolvimento local e territorial sustentável, com ênfase na inclusão social e na promoção do desenvolvimento humano" (BVO, 2013, p. 13). Assim, apesar da utilização do conceito de PECS, passaremos a denominar como programas esportivos a ambos.

5 Os critérios de seleção são relacionados à condição socioeconômica dos candidatos, demonstrando uma intenção de diálogo com as demandas sociais das políticas públicas brasileiras.
} 
Outra frente de aproximação preliminar com a Estação Conhecimento e a Fundação Tênis foi uma série de diálogos rápidos com os gestores e professores dos programas analisados. Foram levantados indícios - no sentido do paradigma indiciário de Carlo Ginzburg (1989) - que podem se relacionar com as dimensões da inclusão social de Donnelly (1996), mas que precisarão ser verificadas de maneiras mais sistemáticas e aprofundadas em campo. As aproximações possíveis são:

01) No âmbito da Dimensão Espacial (diminuição das distâncias sociais e econômicas), encontramos relatos sobre jovens estagiando no próprio programa e recebendo bolsa atleta, ajudando economicamente em suas residências e pela oportunidade de ter acesso a competições de alto rendimento, geralmente inacessiveis.

02) No âmbito da Dimensão Relacional (sentimento de pertencimento e aceitação social), há relatos de melhora na autoestima por causa da participação no programa. Além disso, os jovens criariam um sentimento de comunidade (comunitas), apoiando uns aos outros, independentemente de resultados competitivos.

03) No que se refere à Dimensão Funcional (ampliação de conhecimentos, habilidades e capacidade de compreender fenômenos), há jovens participantes do projeto que se tornaram campeões estaduais e possuidores de recordes, além dos relatos de conhecimentos e responsabilidades que podem ser utilizados no mercado de trabalho e na vida cotidiana.

04) Na Dimensão de Poder da teoria de inclusão social de Donnelly (converter-se em um cidadão consciente da sociedade que vive e ter poder para opinar sobre ela e mudá-la, assumindo um lugar de controle), foram observados relatos de jovens que optaram por prosseguir nos estudos em nível superior, se graduando e atuando como professores, melhorando sua capacidade crítica e se inserindo socialmente como cidadão de direitos.

\section{CONSIDERAÇÕES FINAIS}

Essas aproximações iniciais indicam, tanto no plano teórico quanto no plano empírico, que há a possibilidade de articulação de projetos/programas sociais, valores educacionais olímpicos (representados pela educação olímpica certificada pelo Comitê Internacional Pierre de Coubertin) e inclusão social. Se faz necessário avançar as investigações com a intencionalidade de entender o discurso dos egressos e as respectivas transformações reais confirmadas em suas trajetórias de vida. As futuras pesquisas devem levar em consideração a necessidade de expansão de estudos focando a discussão sobre esporte, educação em valores e sociedade. Apesar da afirmação de que o legado da educação olímpica deveria ser uma ponte entre a busca pela excelência dos atletas de elite, e a busca pelos sonhos de uma criança (Binder, 2012), a inclusão social só seria efetiva a partir da realização de parte desses sonhos em suas trajetórias de vida, justificando o argumento do esporte, da educação olímpica e do projeto/programa social como modificadores de realidades sociais.

\section{REFERÊNCIAS}

Abbagnano, N. (2007). Dicionário de filosofia. São Paulo: Martins Fontes.

Antunes, S. E. (2018). Projetos esportivos de caráter social - um estudo de caso com jovens em conflito com a lei. 2019. 185 f. Tese (Doutorado em Educação Física). Vitória: Programa de Pós-Graduação em Educação Física, Universidade Federal do Espírito Santo. 
Bailey, R. (2005) Evaluating the relationship between physical education, sport and social inclusion, Educational Review, 57:1, 71-90. https://doi.org/10.1080/0013191042000274196

Binder, D. L. (2012) Olympic values education: evolution of a pedagogy, Educational Review, 64:3, 275302. https://doi.org/10.1080/00131911.2012.676539

Breivik, G. (1998) Sport In High Modernity: Sport as a Carrier of Social Values, Journal of the Philosophy of Sport, 25:1, 103-118. https://doi.org/10.1080/00948705.1998.9714572

BVO - Brasil Vale Ouro. (2013) Proposta pedagógica de esporte: Brasil Vale Ouro. Brasília: Fundação Vale, UNESCO.

Carr, D. (1998) What moral educational significance has physical education? A question in need of disambiguation. In: Mcnamee, M.; Parry, J. Ethics and Sport. London: E\&FN Spon.

COI - Comitê Olímpico Internacionl. (2015). Carta Olímpica. Lausanne: Didwedo S.à.R.L.

DaCosta, L.P. (2009) Educação olímpica como metalinguagem axiológica: revisões pedagógicas e filosóficas de experiências internacionais e brasileiras. In: Reppold Filho, A.R.; Magalhães Pinto, L.M.S.; Rodrigues, R.P.; Engelman, S. (Orgs.) Porto Alegre: Ed. UFRGS.

Donnelly, P. (1996) Approaches to Social Inequality in the Sociology of Sport, Quest, 48:2, 221-242. https://doi.org/10.1080/00336297.1996.10484192

Ginzburg, C. (1989). Mitos, emblemas e sinais: Morfologia e história. São Paulo: Cia. Das Letras.

Goellner, S. (2005). Mulheres e futebol no Brasil: entre sombras e visibilidades. Rev. Bras. Educ. Fís. Esp.

Grupe, O. (1990). The Sport Culture and the Sportization of Culture: Identity, Legitimacy, Sense, and Nonsense of Modern Sport as a Cultural Phenomenon. In Fernand Landry et al., eds., Sport...the Third Milleninum, Proceedings of the International Symposium, Quebec City, Canada, May 1990. Sainte-Foy, Quebec City: Les Presses de L'Université Laval.

Kravchychyn, C., \& Oliveira, A. (2015). Projetos e programas sociais esportivos no brasil: uma revisão sistemática. Movimento (ESEFID/UFRGS), 21(4), 1051-1065. https://doi.org/10.22456/1982$\underline{8918.54017}$

Mello, J., Pedretti, A., Caporal, G., Mahique, J., Ferreira, A., Reppold-Filho, A., \& Gaya, A. (2020). Secular trend of sports practice of Brazilian children and young people in the decade of mega-sport events. Journal of Human Sport and Exercise, in press. https://doi.org/10.14198/jhse.2022.171.01

Morente Montero, Á. (2020). Sports training in Ancient Greece and its supposed modernity. Journal of Human Sport and Exercise, 15(1), 163-176. https://doi.org/10.14198/ihse.2020.151.15

Nichols, G. (2007). Sport and crime reduction: the role of sports in tackling youth crime. Londres: Routledge.

Stegeman, H.; Janssens, J. (2004). Introduction. In: Janssens, J., Stegeman, H., Hilvoorde, I. Van et al (eds). Education through Sport - An Overview of Good Practices in Europe. Nieuwegein: Arko Sports Media.

Stigger, M. P., \& Thomassim, L. E. (2013). Entre o "Serve" e o "Significa": Uma Análise sobre Expectativas Atribuídas ao Esporte em Projetos Sociais. LICERE - Revista Do Programa De Pósgraduação Interdisciplinar Em Estudos Do Lazer, 16(2). https://doi.org/10.35699/1981$\underline{3171.2013 .656}$

Vilaça, M.; Gawryszewski, B.; Palma, A. (2015). Crítica à panaceia pedagógico-desportiva. Educação e Filosofia.

Zabala, A. (1998). A prática educativa: como ensinar. Porto Alegre: Artmed.

Zaluar, A. (1994). Cidadãos não vão ao paraíso. Campinas: Ed. da Unicamp. 
